\title{
Research on Performance Appraisal Management Based on University Research Platform
}

\author{
Yuanfei Xue, Ruifang Wang* \\ Shenzhen Polytechnic, Shenzhen, Guangdong, China \\ *Corresponding author: wangtushirui@126.com
}

\begin{abstract}
Performance appraisal management system is widely used in all fields of society. This paper takes the university research platform as the research object, and probes into its performance appraisal management. Through the study of its connotation, characteristics and significance, this paper discusses the status quo and problems of the performance appraisal of the university's scientific research platform, and analyzes the countermeasures on this basis.
\end{abstract}

Keywords: research platform; performance appraisal; strategy

\section{Introduction}

As the main educational position, colleges and universities not only shoulder the responsibility of exporting all kinds of professional talents for the society, but also shoulder the important responsibility of promoting social scientific and technological innovation with their abundant resources of education, talents and technology. In the new era, while carrying out technological innovation, colleges and universities should also pay attention to the innovation of scientific research management methods, so as to provide guarantee for the orderly development of scientific research and teaching work in colleges and universities, and provide important basis for the effective implementation of performance management work in colleges and universities. In order to ensure the quality of scientific research management and enhance its effectiveness and sense of the times, we propose to implement performance assessment management for the scientific research platform of universities, so as to achieve its precision.

\section{Overview of Performance Appraisal Management of University Research Platform}

The main purpose of carrying out performance appraisal management for the university research platform is to comprehensively and objectively reflect the working conditions of the research members through the analysis, evaluation and assessment of the performance indicators of the platform, and to provide incentives for the follow-up research work based on this. The results of performance appraisal can serve as an important basis for the local government to support the scientific research projects of colleges and universities. Colleges and universities can also reform the research platform with poor scientific research results and low output according to the results. This is conducive to improving the level and efficiency of scientific research in universities and avoiding the waste of scientific research resources.

Copyright (C) 2020 by author(s) and Frontier Scientific Research Publishing Inc.

This work is licensed under the Creative Commons Attribution International License (CC BY 4.0).

http://creativecommons.org/licenses/by/4.0/ 
Therefore, in order to promote the good development of the scientific research platform in colleges and universities, it is necessary to introduce the competitive mechanism represented by performance appraisal. In order to ensure the effective development of the performance appraisal management of the university's scientific research platform, we need to combine the characteristics of the university's scientific research work to develop the corresponding performance appraisal index system, so as to refine the performance appraisal work. Generally speaking, we can subdivide the performance appraisal index system into three main indicators, namely talent cultivation index, scientific research index and user service index, and set two and three indicators under each major category (Figure 1).

\begin{tabular}{|c|c|c|}
\hline \multirow{6}{*}{ User service index } & \multirow[b]{2}{*}{ User service time } & Service hours for campus users \\
\hline & & $\begin{array}{c}\text { Service hours for off-campus } \\
\text { users }\end{array}$ \\
\hline & User satisfaction & $\begin{array}{c}\text { Customer satisfaction with the } \\
\text { service }\end{array}$ \\
\hline & \multirow{3}{*}{ Research projects and funding } & Number of research projects \\
\hline & & Research project funding \\
\hline & & $\begin{array}{l}\text { Annual per capita scientific } \\
\text { research funding }\end{array}$ \\
\hline \multirow{3}{*}{ Scientific research index } & \multirow{3}{*}{ Scientific research achievements } & The winning number \\
\hline & & $\begin{array}{c}\text { Number of publications and } \\
\text { papers }\end{array}$ \\
\hline & & Transfer of technology patent \\
\hline \multirow{4}{*}{ Talent cultivation index } & \multirow[b]{2}{*}{ Training of professional talents } & $\begin{array}{l}\text { Total number of classes in the } \\
\text { center }\end{array}$ \\
\hline & & $\begin{array}{l}\text { The number of master's and } \\
\text { doctor's degree candidates in the } \\
\text { center }\end{array}$ \\
\hline & \multirow{2}{*}{ Training } & Number of lectures and training \\
\hline & & Total number of trainees \\
\hline
\end{tabular}

Figure 1. Performance appraisal index system

After the establishment of the performance appraisal index system of the scientific research platform, it is necessary to assign the score weight of individual indicators. Colleges and universities can allocate by themselves according to their own strength and the construction and use of the research platform. Two principles need to be grasped here: first, give prominence to the scientific research and teaching of large equipment service schools, and take the user service of scientific research platform as the key evaluation object; second, pay attention to the actual work effect of the research platform, and give a certain proportion to talent training and research achievements.

\section{Current Situation and Problems of Performance Appraisal Management of University}

\section{Research Platform}

\subsection{The situation}

The uniqueness of universities determines that their scientific research work has the characteristics of long cycle and output lag. Therefore, it is difficult for colleges and universities to make a timely, effective and reasonable evaluation of the assessment content and its implementation. At present, there are three general application modes of performance assessment of university research platform. First, the scientific research performance appraisal management model based on scientific research input-output index. This assessment mode is characterized by wide evaluation range, more evaluation indexes, and weak operability in the specific application process. Second, the average performance model. The scientific research performance of university teachers is calculated by comparing certain coefficient with the number of scientific research achievements of teachers and the average award of scientific research team. This assessment mode 
pays too much attention to the research results, ignores the long-term hard work and efforts of researchers, and lacks

performance considerations for the daily workload of researchers, which makes it difficult to motivate the enthusiasm of researchers. Third, the performance appraisal mode with key evaluation indexes as the main indicators. With the combination of quantitative evaluation and qualitative evaluation, the construction of performance model is feasible. However, it is difficult for managers to determine the weight of each performance index due to the different actual conditions of each university.

\subsection{The problems}

University research platform is a very open resource sharing platform. It can not only provide teachers and students with teaching and research support, including experimental instruments, laboratories, research materials, project testing, specimen collection, etc., but also open and share these high-quality scientific research resources to the society to play its great value. In terms of the actual situation of the management of scientific research platforms in colleges and universities, it is difficult for most of them to fully open and share to the society due to the influence of various practical factors. This not only restrains the play of the value of the scientific research platform in colleges and universities, but also reduces the guiding role of social demand and development in the improvement and construction of the scientific research platform in colleges and universities. At the same time, the imperfection of the performance appraisal management system will also lead to the low working efficiency of the university's scientific research platform, and it is difficult to implement a series of work such as scientific research data measurement, project detection and specimen collection effectively and quickly. Therefore, as soon as possible to establish a set of effective university scientific research platform performance assessment management system has become a major issue to be solved.

\section{The Strategy of Performance Appraisal Management of University Research Platform}

The performance assessment management of university research platform mainly involves the integration of research resources, operation management and service effectiveness. In order to improve the assessment management system, we need to start from three aspects of assessment objects, management system and assessment indicators, so as to promote the optimization and integration of scientific research resources in universities.

4.1Expand the scope of sharing scientific research resources in colleges and universities

Under the background of resource-sharing and joint development, we should always adhere to the principle of open and shared, extensively absorb those qualified, capable, willing and resource-rich research platforms, and make clear the qualifications, capabilities and responsibilities of research institutions under the role of coordination mechanism of research platforms. In order to solve the dilemma of "information island" of university research platform, we should cooperate with relevant departments of culture, education and scientific research under the unified command of the local government to build and introduce scientific research information database and scientific research hardware facilities. In addition, with the help of the Internet link function, the characteristic database of other secondary research service sites and the research project resource center should be linked to the university research platform, so as to effectively expand the width and depth of the university research platform construction.

4.2Improve performance assessment indicators for university research platforms

The implementation of the two sets of quantitative performance evaluation indicators mainly include: first, from the angle of the horizontal between the service platform of scientific research in higher educational institutions and the secondary service site in job performance, function positioning, service ability, the scientific research level to introduce 
two different sets of assessment indexes and assessment management system, to ensure the scientific nature, the rationality of the performance appraisal. This is also conducive to improve the work efficiency and reduce the cost of assessment. Second, increase the assessment indicators such as the amount of data processing, the amount of item detection, the amount of specimen collection and the amount of original text transmission, so as to highlight the value and function of the assessment data. According to the grade division of the assessment results, the university scientific research personnel and projects should be given appropriate scientific research subsidies. In addition, it is necessary to scientifically quantify the contents of the first, second and third indexes of the performance assessment of the university's scientific research platform based on the comprehensive conditions of running schools and scientific research, so as to ensure the objectivity and impartiality of the performance assessment of the university's scientific research platform while assigning different weights and scores to each index. Third, cooperate with multiple departments to provide reference services for the construction of university research platforms, so as to improve the utilization efficiency of research platform resources. To this end, we can rely on the advantages of Internet technology, and cooperate with the government, universities, scientific research and other departments to establish a joint transmission service mechanism of scientific research resources, so as to enable teachers, students and social users to obtain more convenient information related to the scientific research platform of universities, so as to avoid the contradiction between proprietary intellectual property rights of scientific research results and sharing of resources.

\subsection{Increase support for performance appraisal management of university research platforms}

The construction and assessment of university research platform involves a wide range, which requires a lot of manpower, material resources and financial resources to be invested under the joint efforts of multiple parties, so as to ensure the maximum play of the university research platform capacity. At present, most colleges and universities in China plan the use of the research platform funds by the way of planned project contract management, but it leads to poor budget stability and difficult to guarantee the implementation efficiency. Colleges and universities should actively improve and clarify the fund management contents such as performance assessment, organization and operation, and fund use in accordance with the relevant system requirements of the performance assessment management of their research platforms. Specifically speaking, the first is to clarify the principle of continuous funding support for the performance of university research platform. According to the relevant requirements of financial stability support in the plan for the optimization and integration of national science and technology innovation base, the funding of scientific research platform in colleges and universities should be given stable support to ensure the demand for relevant materials and human resources in the process of scientific research platform construction and performance management. Second, according to the relevant requirements of the government's financial fund reform, the relationship between the departments of finance, colleges and universities and the competent departments of education should be straightened out, so as to improve the application efficiency of the financial fund of the scientific research platform of colleges and universities. Thirdly, a performance appraisal management system should be established according to the characteristics of the university research platform. By linking the assessment results with the budget of scientific research projects, the scientific research achievements of the research platform service are highlighted, which serves as an important basis for the recognition and financial support of advanced collectives and individuals. In addition, colleges and universities should make relevant regulations to clarify the target and scope of the performance appraisal bonus, so as to stimulate the enthusiasm of university researchers. 


\section{Conflicts of Interest}

The author declares no conflicts of interest regarding the publication of this paper.

\section{References}

[1] Chen J., Zhang H.X. and Zhu J., et al. (2019). Research on Performance System of Public Service Platform for Hospital Scientific Research Based on "Ord-virtual Currency" Model. China Hospital, 23 (11) : 10-12.

[2] Huang Y., Luo L.N. and Li X.h., et al. (2019). On the Performance Appraisal of Scientific Research Institutes. Journal of Science and Technology Entrepreneurship, 32 (09) : 77-78.

[3] Deng Y.Q. (2019). Research on Some Problems of Scientific Research Performance Management. Science and Technology Management Research, 39 (06) : 100-107.

[4] Pan J.X., Bin C. and Chen Y.L., et al. (2018). Status Quo and Countermeasures of Performance Assessment of Secondary Service Stations of Science and Technology Literature Platform -- A Case Study of Guangxi Science and Technology Literature Information Sharing and Service Platform. Library Circle, (02) : 20-25.

[5] Teng W.J and Dang Y.1. (2010). Research on Performance Appraisal System of Scientific Research Management in Universities. Economist, (06) : 99-100. 